\title{
Resolutions and Declarations in an Era of Global Surgery
}

\author{
Kelly McQueen ${ }^{1} \cdot$ David A. Watters $^{4} \cdot$ Villiami Tangi $^{2,3}$
}

Published online: 26 July 2016

(c) Société Internationale de Chirurgie 2016

Five billion of the world's 7 billion people do not have access to safe, affordable surgery and anaesthesia care when needed. In 2015, the World Health Assembly (WHA) recognized the importance of the role of emergency and essential surgical care and safe anaesthesia to universal health coverage by unanimously passing resolution 68/15 [1]. Many nations and representative bodies of surgery and anaesthesia collaborated to support the resolution. The Bangkok Declaration is a summary of the events of 2015 that will serve as a reminder to future generations of the history of surgery and anaesthesia within global health, and the great effort behind the Global Surgical Era 2016-30.

The World Health Assembly (WHA) resolution 68/15 marks only the beginning of the road towards ensuring most of those 5 billion will gain access to safe, timely and affordable surgery, and anaesthesia care by 2030. There is a need for much effort, collaboration, and funding to ensure that successful models of scale-up in capacity and capability in surgical and anaesthesia care are introduced to low- and low-middle-income countries. The Lancet Commission for Global Surgery (LCoGS) has identified key messages, made recommendations, and agreed indicators to make, manage, and measure progress [2]. The evidence was presented that surgery and anaesthesia care

Kelly McQueen

kelly.mcqueen@vanderbilt.edu

1 Departments of Anesthesiology and the Global Initiative, Vanderbilt University, Nashville, TN, USA

2 Pacific Islands Surgeons Association, Apia, Samoa

3 Surgery, Vaiola Hospital, Nuku'alofa, Tonga

4 Royal Australasian College of Surgeons, Melbourne, Australia avert premature death, prevent disability, and correct deformity. They can be delivered cost-effectively with a good return on investment to the economic advantage of the families, communities, and countries concerned. The World Health Organization (WHO) [3] and The World Bank [4] have agreed to adopt the recommended indicators identified by the LCoGS. WHO through the Global Initiative on Emergency and Essential Surgical Care (GIEESC) will play a central role in authorizing and coordinating initial and ongoing progress, as well as monitoring outcomes. To be successful, the global surgery and anaesthesia communities must unite to such a common vision and agree to collaborate, even when inevitable conflicts of interest arise. The governments of low- and middle-income countries (LMICs) and their ministries of health need to develop their strategy for surgical and anaesthesia care within their National Health Plans and secure the investment required to finance the workforce and resources needed to deliver by 2030 .

The Bangkok Declaration was written to be inclusive of the messages and recommendations of WHA 68/15 [1], the Lancet Commission for Global Surgery [2], and the World Bank's Disease Control Priorities $3^{\text {rd }}$ Edition volume on Essential Surgery [5]. It was proposed during the Alliance for Surgery and Anaesthesia Presence (ASAP) Section of the International Surgical Society (ISS) Congress convened in Bangkok, August 2015. By June 2016, the Declaration had attracted 62 signatories including 15 International Surgical Colleges or Associations, 20 National or International Associations/Societies of Anaesthetists, as well as Universities, Global Health Institutes and Humanitarian Special Interest Groups.

Declarations are documents drafted and ratified by interested empowered groups of individuals and 
organizations, for the purpose of promoting a framework or concept of importance to an initiative or movement. The beneficence intent is at the core of such documents, historically targeted towards an improvement of the human condition. For example, the 1946 constitution of WHO defined health as "a state of complete physical, mental, and social well-being and not merely the absence of disease or infirmity [6]". It regarded health as a human right by declaring "The enjoyment of the highest attainable standard of health is one of the fundamental rights of every human being without distinction of race, religion, political belief, economic or social condition". The United Nation's Universal Declaration of Human Rights in 1948 included article 25 that spoke to the right of everyone to enjoy "a standard of living adequate for the health and well-being of himself and of his family" [7]. In 1978, the Alma Ata Declaration made by the International Conference of Primary Health Care meeting in Kazakstan, then part of the USSR, further promised equality and access to the most basic components of human existence-health, dignity, and social well-being [8]. In the twenty-first century, recent declarations have built these fundamental and accepted principles but focused on specific challenges or related health outcomes, for example the 2005 Paris Declaration on Aid Effectiveness [9] and the 2010 Helsinki Declaration on Patient Safety in Anaesthesia [10]. Previous WHA resolutions relevant to surgical care have included WHA 56.24 on violence and health, 58.23 on disability, 60/22 on trauma and emergency care services, 64.6 on health systems strengthening, and 66.10 on noncommunicable diseases [1]. However, resolution 68/15 was the first to cover surgical and anaesthesia care specifically, and lend credibility to WHO's Global Initiative for Emergency and Essential Surgical Care, first established in 2005.

Declarations related to safe anaesthesia and surgery that represent consensus and achieve support from Colleges, Associations, and Societies have the potential to define an historical landmark. The contribution of Global Surgery will be critical to achieving the United Nations Post-2015 Sustainable Development Goals (SDG), particularly the third goal to "ensure healthy lives and promote well-being for all at all ages". Endorsed in September 2015, these SDGs are likely to drive governments to strengthen their health systems which will include the provision of emergency and essential surgical and anaesthesia care.

The August 2015 Bangkok Declaration was based upon the 2014 Amsterdam Declaration [11], but had the benefit of being informed by, the LCoGs [2] and the WHA Resolution 68/15 [1], the Disease Control Priorities in
Developing Countries Essential Surgery [5]. One of the issues raised when agreeing to sign it by the Surgical Colleges and Anaesthetic Societies was whether this Declaration should be updated at regular intervals in the future rather than being superseded by a series of fresher but quickly forgotten ones. Time will tell, but the intention is for the Bangkok Declaration to last, with revisions to be made as necessary, as long as the Declaration articulates the key messages, the intent, and can be a rallying point that maps the road ahead and our willingness to go hand in hand.

The Bangkok Declaration articulates the vision, is based on the best evidence available in 2015 , and commits signatories to act cohesively and collaboratively to strengthen emergency and essential surgical care as a component of universal health coverage. Only then will everyone realize their fundamental human right to enjoy the best possible health and well-being.

\section{References}

1. World Health Assembly (2016) Strengthening emergency and essential surgical care as a component of universal health coverage. Resolution 68/15. http://www.who.int/surgery/wha-eb/en/. Last accessed 6 June 2016

2. Meara JG, Leather AJ, Hagander L et al (2015) Global Surgery 2030: evidence and solutions for achieving health, welfare, and economic development. Lancet 386(9993):569-624

3. World Health Organisation Global Reference List 100 Core Health Indicators (2015). http://www.who.int/healthinfo/indica tors/2015/en/. Last accessed 6 June 2016

4. The World Bank (2016) Data-Indicators. http://data.worldbank. org/indicator. Last accessed 6 June 2016

5. Debas HT, Donkor P, Gawande A, Jamison DT, Kruk ME, Mock CN (2015). Disease control priorities, vol 1, 3rd edn. Essential Surgery. Washington, DC: World Bank. https://openknowledge. worldbank.org/handle/10986/21568. Last accessed 6 June 2016

6. Editorial (1946) A Magna Carta for World Health. Am J Public Health Nations Health 36(9):1041-1045

7. United Nations (2015) Universal Declaration on Human Rights. http://www.un.org/en/universal-declaration-human-rights. Accessed November 2015

8. World Health Organization (2016) Alma Ata Declaration. www. who.int/publications/almaata_declaration_en.pdf. Accessed 6 June 2016

9. OECD (2016) Paris Declaration for Aid Effectiveness. https:// www.oecd.org/dac/effectiveness/45827300.pdf. Accessed 6 June 2016

10. Mellin-Olsen J, Staender S, Whitaker DK, Smith AF (2010) The Helsinki declaration on patient safety in anaesthesiology. Eur $\mathbf{J}$ Anaesthesiol 27(7):592-597. doi:10.1097/EJA.0b013e32833b1adf

11. Botman M, Meester RJ, Voorhoeve R, Mothes H, Henry JA, Cotton MH, Lane RHS, Jani PG, Hedj HA, Ismail EA (2015) The Amsterdam Declaration on essential surgical care. WJS 39:1335-1340. doi:10.1007/s00268-015-3057-x 